\title{
Lei 12.760/2012: estruturação normativa e análise da eficácia de sua aplicação no Noroeste do Rio Grande do Sul
}

\author{
Law 12.760/2012: normative structure and analysis \\ of the effectiveness of its application in the Northwest \\ of Rio Grande do Sul
}

\author{
Junior de CAMpos Junges \\ Universidade de Cruz Alta - UNICRUZ \\ Vanessa de CAmpos Junges \\ Universidade Federal de Santa Maria - UFSM \\ Lauren Silva Agertt Junges \\ Universidade Estadual do Rio Grande do Sul - UERGS
}

Resumo O debate sobre a aplicabilidade da Lei Seca no Brasil ainda é alvo de muita polêmica, os estudos existentes relacionados ao tema não demonstram a eficiência ou a ineficiência da Lei. Em razão disso, o estudo teve como objetivo analisar a estrutura e a eficácia da nova lei seca na região noroeste do Rio Grande do Sul, no período de 2012 a 2016. O método utilizado foi uma pesquisa quantitativa e descritiva; os dados foram coletados por meio de fontes secundárias, e analisados estatisticamente. Os principais resultados apontam que a referida norma tem se apresentado eficiente na redução de mortes e lesões corporais no trânsito, haja vista que os índices avaliados se reduziram gradativamente.

Palavras-chave: Direito Penal do Risco. Trânsito. Álcool. Entorpecentes. MorTALidADE.

Abstract The debate on the applicability of the Seca Law in Brazil is still subject to much controversy, existing studies related to the subject do not demonstrate the efficiency or inefficiency of the Law. Therefore, the study had as objective to analyze the structure and effectiveness of the new drought of the law in the northwest of Rio Grande do Sul, between 2012 and 2016. The me- 
thod used was a quantitative and descriptive research; the data were collected by secondary sources and analyzed statistically. The main results indicate that the aforementioned standard has been effective in reducing deaths and injuries in traffic, since the indexes analyzed were gradually reduced.

Key-words: Criminal Law of Risk. Traffic. Alcohol. Narcotics. Mortality.

\section{INTRODUÇÃo}

O consumo de álcool e entorpecentes com o passar do tempo tem se elevado significativamente, o primeiro (lícito), popularizou-se como símbolo de diversão, já o segundo (ilícito), por sua vez, vem ganhando espaço frente à crise na segurança pública que se prolifera no país. Os entorpecentes, assim como o álcool, ganharam papel de destaque na aplicação da Nova Lei Seca (Lei 12.760/2012) que, ao contrário da Lei de Tóxicos (Lei 11.343/2006), pune severamente os usuários, desde que conduzam veículos sob o efeito de drogas. Dessa forma, tal consumo tem sido motivo de preocupação por parte das autoridades no país, pois, quando associado à condução de veículos, eleva-se o risco de acidentes de trânsito, em virtude da alteração da capacidade psicomotora, gerada pela ingestão dessas substâncias.

Em 2008, entrou em vigor a Lei № 11.705 (Lei Seca), que estabelecia limites mais severos aos motoristas que ingeriam álcool ou substâncias psicoativas (entorpecentes) na condução de veículos automotores, bem como, impôs algumas regras aos estabelecimentos lindeiros à rodovias, quanto à comercialização de bebidas alcoólicas. Essa Lei vigorou até o ano de 2012, quando fora alterada pela Lei $N^{\circ}$. 12.760/12, popularmente conhecida como a Nova Lei Seca, que provocou mudanças ainda mais rígidas no Código de Trânsito Brasileiro, das quais grande parte ainda se encontra em vigor. Diante do exposto, aponta-se a seguinte problemática: a nova lei seca demonstrou eficácia na região noroeste do Rio Grande do Sul no período de 2012 a 2016 ?

Assim sendo, o estudo teve como objetivo analisar a estrutura e a eficácia da nova lei seca na região noroeste do Rio Grande do Sul, no período de 2012 a 2016. Justifica-se a relevância do estudo, uma vez que, no Estado do Rio Grande do Sul, assim como no Brasil, o trânsito 
é um dos principais responsáveis por índices de mortes e lesões corporais. Ainda, a fiscalização dos crimes, cometidos no volante, sempre foi alvo de elogios e críticas, contudo, a falta de informação da população no que se refere à estatística dos acidentes acaba causando certa aversão à Lei por parte dos leigos no assunto. Dessa forma, faz-se necessário um estudo aprofundado da norma, a fim de que se possa divulgar sua efetividade e discutir os critérios que compõem seu texto, em vista de propor novas alternativas na aplicação da mesma.

Desta feita, analisar os dados referentes a mortes e lesões corporais no trânsito, é imprescindível, pois, ao conflitá-los com o crime do Artigo 306 do Código de Trânsito Brasileiro (CTB), nos anos subsequentes à implantação da referida Lei, se verificará a eficácia ou a ineficácia da norma. Em suma, trazer o tema Nova Lei Seca para o centro das discussões e demonstrar sua importância perante a proteção ao bem maior: $a$ vida, é de grande relevância, visto que, poderá oportunizar novos estudos na área do Direito. Dos quais, alternativas poderão ser propostas a fim de garantir índices de maior eficiência em sua aplicabilidade, bem como, rever o rigor punitivo ao se tratar de crimes de perigo abstrato. Ademais, também é importante frisar que o tema se insere na temática do direito penal do risco, suas variantes e problemas dogmáticos, razão pela qual se inicia a abordagem a partir desta perspectiva.

\section{A sociedade do Risco e os CRIMES de PERIgo abStrato/ CONCRETO}

O risco sempre fez parte da natureza humana, e será sempre uma qualidade diante de variações de possibilidade, visto que, primitivamente em estado de natureza, o risco era individual, diferente do risco à ordem social que se apresenta como coletivo. Essa preocupação com a coletividade originou a sociedade do risco, em meados da revolução industrial. Desta feita, a livre concorrência gerou a produção e a distribuição em larga escala, a qual deveria ser acompanhada pelo consumo, sob pena de perecimento por obsolescência. Assim, surge a incerteza e a insegurança, que obrigaram o ser humano a aceitar o risco como fator indispensável ao desenvolvimento econômico e social (BOTTINI, 2010, p. 34, 35, 36). 
É correto afirmar que na contemporaneidade, bem como, nos primórdios de nossa existência, o risco se mantém inerente a toda manifestação humana. Contudo, existem dois tipos de riscos, os permitidos e os proibidos. O primeiro se refere aos riscos aceitos ou tolerados pelo Estado, conforme exemplificado:

Quando o ordenamento jurídico permite e regula a construção de uma ponte ou a fabricação de um automóvel, um avião, um navio, uma arma de fogo etc., o legislador tem consciência de que a utilização desses bens, ainda que de forma normal, carrega riscos a interesses que ele mesmo pretende proteger (JESUS, 2011, p. 320).

Assim sendo, aquele que efetuar conduta de risco tolerada por nosso ordenamento não poderá ser penalizado por possíveis danos, haja vista que não há norma que o defina, prevalecendo o princípio da legalidade. Já o segundo caso se refere aos riscos repudiados pelo Estado, os quais possuem positivação em norma legal, ou seja, a sanção será aplicada para a ação que criar um perigo reprovado pelo ordenamento que, implica tipicidade da conduta, seja dolosa ou culposa (SILVA, 2017, p. 4). Ainda nesse viés, é importante destacar que em alguns casos, embora a conduta seja reprovada por nosso ordenamento, poderá, ainda assim ser lícita. É o caso da lesão corporal, prevista no Artigo 129 do Código Penal (1940), que ao ser praticada em luta de boxe (esporte), deixa de ser reprovável e adquire aceitação social (exclusão da ilicitude), deixando de ser reprovado o dano causado a terceiro (competidor).

O risco na sociedade contemporânea passou a ser criado pela própria organização coletiva, ou seja, repercute nas atividades humanas, o perigo não mais se refere a algo externo ao meio social, mas sim interno, ou seja, faz parte da sociedade, e está inserido nela por meio das atividades exercidas, que podem ser reguladas, normatizadas e direcionadas a esses comportamentos (BOTTINI, 2010, p. 37).

Dessa forma, as condutas positivadas na sociedade do risco constituem-se basicamente de crimes de perigo abstrato ou concreto, diferenciando-se dos crimes de dano, conforme explica Bitencourt: 
Crime de dano é aquele cuja consumação é necessária a superveniência da lesão efetiva do bem jurídico. A ausência desta pode caracterizar a tentativa ou um indiferente penal, como ocorre com os crimes materiais (homicídio, furto, lesão corporal). Crime de perigo é aquele que se consuma com a simples criação do perigo para o bem jurídico protegido, sem produzir um dano efetivo [...] (BITENCOURT, 2003, p. 148).

No que tange aos crimes de perigo abstrato, pode-se dizer que se caracterizam por uma conduta de probabilidade de dano, ou seja, se baseia na simples presunção, não necessita ser provado, pois a lei reprova a simples prática da conduta perigosa (BITENCOURT, 2003, p. 148). Aplicando o crime de perigo abstrato em nossa temática de estudo (Lei $\mathrm{N}^{\mathrm{o}} .12 .760$ / 2012), pode se verificar a presença do mesmo na simples aplicação da infração do Artigo 165, bem como, na incidência do Artigo 306 do Código de Trânsito Brasileiro, visto que, se pune a conduta de conduzir veículo com a capacidade psicomotora alterada, objetivando-se a precaução de possíveis riscos que possam ser causados a terceiros.

Perigo abstrato, em que a lei descreve uma conduta e presume a existência do perigo sempre que tal conduta se realize, independentemente da comprovação de que alguém efetivamente tenha sofrido risco, não admitindo, ainda, que se faça prova em sentido contrário. Nessa modalidade de delito, o tipo penal simplesmente descreve a conduta perigosa [...] (GONÇALVES, 2011, p. 201).

Já os crimes de perigo concreto devem ser comprovados de forma que seja concretizada a situação de risco sofrida pelo bem jurídico tutelado (BITENCOURT, 2003, p. 148). Exemplificando o supracitado, pode-se dizer que o crime de perigo concreto está presente em situações onde o condutor com capacidade psicomotora alterada, envolve-se em acidente de trânsito com danos materiais, razão pela qual se entende que a conduta gerou perigo concreto à integridade física de terceiros, passível das sanções previstas no Artigo 165 e 306 do CTB. 
Analisadas as principais diferenças entre crimes de perigo (abstrato e concreto), é importante situar a questão no universo da evolução epistemológica do direito penal, ainda que a mesma não seja o objeto central da presente pesquisa. Isto porque a ideia do risco em matéria penal não é totalmente pacificada pela teoria finalista da ação (mais aceita no Brasil), mas sim está relacionada à teoria da imputação objetiva.

A teoria finalista da ação é a mais aceita no sistema penal brasileiro, conforme explica Bitencourt:

Segundo a concepção finalista, somente são produzidas finalisticamente aquelas consequências a cuja realização se estende a direção final. Em outros termos, a finalidade - vontade de realização - compreende, segundo Welzel, o fim, as consequências que o autor considera necessariamente unidas à obtenção do fim, e aquelas previstas por ele como possíveis e com cuja produção contava. Ficam fora da vontade de realização, por conseguinte, aquelas consequências que o autor prevê como possíveis, mas confia sinceramente que não se produzam (BITENCOURT, 2003, p. 157).

Por meio dessa teoria, busca-se punir as consequências, ou seja, o resultado final de determinada conduta, ao contrário da teoria do risco, que antecipa a tutela penal. No entanto, embora o direito penal do risco não esteja pacificado em nosso ordenamento, vem sendo discutido e inserido em alguns crimes específicos, por exemplo, delitos de trânsito, onde se visa precaver a conduta de risco, preservando bens maiores: a vida e a integridade física.

\section{Nova Lei Seca}

O legislador, ao criminalizar a ação de conduzir veículo automotor com a capacidade psicomotora alterada (Art. 306 do Código de Trânsito Brasileiro), visa precaver o possível resultado danoso, punindo, dessa forma, a conduta geradora de perigo (abstrato ou concreto).

Nota-se também a preocupação do legislador em não utilizar unicamente do direito penal como meio de reprimir determinada conduta, haja vista que foram estabelecidos parâmetros técnicos para a imposi- 
ção de medidas administrativas, aplicando-se a criminalização apenas nos casos que extrapolem os limites estipulados pela legislação, conforme observado no desenvolvimento do estudo.

No que tange à evolução da Nova Lei Seca, pode-se dizer que o Código de Trânsito Brasileiro (CTB) - Lei 9.503, desde a sua sanção, no ano de 1997, trazia, em seu texto, artigos específicos referentes à embriaguez e ao uso de substâncias entorpecentes quando ao volante, sendo estes os Artigos 165 (Infração de trânsito), e Artigo 306 (Crime).

Contudo, no ano de 2007, mediante a sanção do decreto 6.117/2007 que dispunha em sua ementa: "Aprova a Política Nacional sobre o Álcool, dispõe sobre as medidas para redução do uso indevido de álcool e sua associação com a violência e criminalidade, e dá outras providências", passou-se a dar maior atenção aos delitos envolvendo a embriaguez ao volante. Até que em 19 de junho de 2008 entrou em vigor a popular "Lei Seca" (Lei 11.705), a qual restringia o uso e a propaganda de bebidas alcoólicas, bem como, alterava alguns artigos do Código de Trânsito Brasileiro (CTB), referentes à penalização da embriaguez, tornando-os mais severos.

Tal severidade na aplicação da lei era uma questão de saúde pública, bem como, um clamor popular, conforme destaca Lima (2012, p. 14), ao afirmar que no ano de 2002 houve um aumento significativo do número de mortes no trânsito. Sendo que, em 2007, os óbitos ultrapassaram o número de 35 mil, além das 350 mil pessoas que restaram lesionadas. $\mathrm{O}$ fator alcoolemia fazia-se presente em $70 \%$ dos casos de óbito, sendo que o trânsito na época era a $3^{\mathrm{a}}$. maior causa de mortes no país.

Após ser implantada no Brasil, a Lei Seca foi alterada duas vezes, a primeira em 2012, por meio da Nova Lei Seca (Lei 12.760/2012), e a segunda em 2016, quando sofreu nova alteração nos valores das infrações dos Artigos 165 e Artigo 165-A (substituiu o Art. 277 - recusa ao etilômetro), por intermédio da Lei 13.281/2016. Ambas as alterações tornaram ainda mais rígida a aplicabilidade da norma, sendo que a primeira alteração dada pela lei $12.760 / 12$ pode ter sido influenciada fortemente pela campanha: "Pacto Nacional pela Redução dos Acidentes no Trânsito - Pacto pela Vida", iniciada em 2011. 
A referida campanha foi motivada pelo compromisso que o país assumiu, em 2011, com a Organização Pan-Americana de Saúde (OPAS) e a Organização Mundial de Saúde (OMS), por meio da adesão ao Plano de Ação da Década de Segurança no Trânsito 2011-2020, conforme noticiado no site da ONU Brasil:

Foi lançada em maio de 2011 a Década de Ação pela Segurança no Trânsito 2011-2020, na qual governos de todo o mundo se comprometem a tomar novas medidas para prevenir os acidentes no trânsito, que matam cerca de 1,3 milhão de pessoas por ano.

Trata-se da nona causa de mortes em todo o mundo. Além disso, os acidentes no trânsito ferem de 20 a 50 milhões de pessoas a cada ano. Em muitos países, os cuidados de emergência e outros serviços de ajuda às vítimas do trânsito são inadequados.

A Organização Pan-Americana de Saúde/Organização Mundial de Saúde (OPAS/OMS) coordena os esforços globais ao longo da Década e monitora os progressos a níveis nacional e internacional. A agência também oferece apoio às iniciativas que têm objetivos como a redução do consumo de bebidas alcoólicas por motoristas, o aumento do uso de capacetes, cintos de segurança e a melhoria dos atendimentos de emergência [...].

Em suma, a Nova Lei Seca alterou diversos artigos do Código de Trânsito Brasileiro, contudo os de maior relevância, e objetos deste estudo, são os seguintes artigos: 165, 165-A e 306, que serão minuciosamente detalhados.

O Artigo 165 do CTB se refere à infração de trânsito (Dirigir sob a influência de álcool ou de qualquer substância psicoativa que determine dependência), a qual poderá ser comprovada de três maneiras: teste do etilômetro, exame clínico (prova pericial) ou prova testemunhal (vídeos, fotos, testemunho policial).

No que se refere ao teste do etilômetro, o Conselho Nacional de Trânsito (CONTRAN), dispôs na Resolução No $.432 / 2013$ uma tabela de valores referenciais para o etilômetro, a qual delimita os índices da simples infração de trânsito até o enquadramento no crime do Artigo 306 do CTB. 
LEI 12.760/2012: ESTRUTURAÇÃo NORMATIVA E ANÁLISE DA EFICÁCIA de sua aplicação no Noroeste do Rio Grande do Sul

Tabela 1 - Índices do Etilômetro

\begin{tabular}{|c|c|c|}
\hline $\begin{array}{c}\mathrm{MR} \\
\mathrm{mg} / \mathrm{L}\end{array}$ & $\begin{array}{l}\mathrm{VC}^{*} \\
\mathrm{mg} / \mathrm{L}\end{array}$ & \\
\hline 0,05 & 0,01 & \multirow{29}{*}{$\stackrel{3}{3}$} \\
\hline 0,06 & 0,02 & \\
\hline 0,07 & 0,03 & \\
\hline 0,08 & 0,04 & \\
\hline 0,09 & 0,05 & \\
\hline 0,10 & 0,06 & \\
\hline 0,11 & 0,07 & \\
\hline 0,12 & 0,08 & \\
\hline 0,13 & 0,09 & \\
\hline 0,14 & 0,10 & \\
\hline 0,15 & 0,11 & \\
\hline 0,16 & 0,12 & \\
\hline 0,17 & 0,13 & \\
\hline 0,18 & 0,14 & \\
\hline 0,19 & 0,15 & \\
\hline 0,20 & 0,16 & \\
\hline 0,21 & 0,17 & \\
\hline 0,22 & 0,18 & \\
\hline 0,23 & 0,19 & \\
\hline 0,24 & 0,20 & \\
\hline 0,25 & 0,21 & \\
\hline 0,26 & 0,22 & \\
\hline 0,27 & 0,23 & \\
\hline 0,28 & 0,24 & \\
\hline 0,29 & 0,25 & \\
\hline 0,30 & 0,26 & \\
\hline 0,31 & 0,27 & \\
\hline 0,32 & 0,28 & \\
\hline 0,33 & 0,29 & \\
\hline 0,34 & 0,30 & \multirow{18}{*}{ 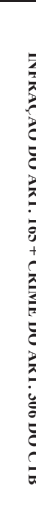 } \\
\hline 0,35 & 0,31 & \\
\hline 0,36 & 0,32 & \\
\hline 0,37 & 0,33 & \\
\hline 0,38 & 0,34 & \\
\hline 0,39 & 0,35 & \\
\hline 0,40 & 0,36 & \\
\hline 0,41 & 0,37 & \\
\hline 0,42 & 0,38 & \\
\hline 0,43 & 0,39 & \\
\hline 0,44 & 0,40 & \\
\hline 0,45 & 0,41 & \\
\hline 0,46 & 0,42 & \\
\hline 0,47 & 0,43 & \\
\hline 0,48 & 0,44 & \\
\hline 0,49 & 0,45 & \\
\hline 0,50 & 0,46 & \\
\hline 0,51 & 0,46 & \\
\hline
\end{tabular}

\begin{tabular}{|c|c|}
\hline $\begin{array}{c}\mathrm{MR} \\
\mathrm{mg} / \mathrm{L}\end{array}$ & $\begin{array}{l}\mathrm{VC}^{*} \\
\mathrm{mg} / \mathrm{L}\end{array}$ \\
\hline 0,54 & 0,49 \\
\hline 0,55 & 0,50 \\
\hline 0,56 & 0,51 \\
\hline 0,57 & 0,52 \\
\hline 0,58 & 0,53 \\
\hline 0,59 & 0,54 \\
\hline 0,60 & 0,55 \\
\hline 0,61 & 0,56 \\
\hline 0,62 & 0,57 \\
\hline 0,63 & 0,58 \\
\hline 0,64 & 0,58 \\
\hline 0,65 & 0,59 \\
\hline 0,66 & 0,60 \\
\hline 0,67 & 0,61 \\
\hline 0,68 & 0,62 \\
\hline 0,69 & 0,63 \\
\hline 0,70 & 0,64 \\
\hline 0,71 & 0,65 \\
\hline 0,72 & 0,66 \\
\hline 0,73 & 0,67 \\
\hline 0,74 & 0,68 \\
\hline 0,75 & 0,69 \\
\hline 0,76 & 0,69 \\
\hline 0,77 & 0,70 \\
\hline 0,78 & 0,71 \\
\hline 0,79 & 0,72 \\
\hline 0,80 & 0,73 \\
\hline 0,81 & 0,74 \\
\hline 0,82 & 0,75 \\
\hline 0,83 & 0,76 \\
\hline 0,84 & 0,77 \\
\hline 0,85 & 0,78 \\
\hline 0,86 & 0,79 \\
\hline 0,87 & 0,80 \\
\hline 0,88 & 0,81 \\
\hline 0,89 & 0,81 \\
\hline 0,90 & 0,82 \\
\hline 0,91 & 0,83 \\
\hline 0,92 & 0,84 \\
\hline 0,93 & 0,85 \\
\hline 0,94 & 0,86 \\
\hline 0,95 & 0,87 \\
\hline 0,96 & 0,88 \\
\hline 0,97 & 0,89 \\
\hline 0,98 & 0,90 \\
\hline 0,99 & 0,91 \\
\hline 1,00 & 0,92 \\
\hline
\end{tabular}

\begin{tabular}{|c|c|c|}
\hline $\begin{array}{c}\mathrm{MR} \\
\mathrm{mg} / \mathrm{L}\end{array}$ & $\begin{array}{l}\mathrm{VC}^{*} \\
\mathrm{mg} / \mathrm{L}\end{array}$ & \\
\hline 1,03 & 0,94 & \multirow{47}{*}{ 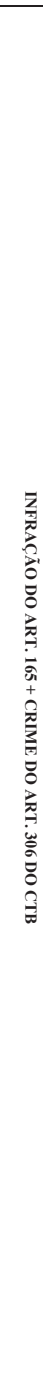 } \\
\hline 1,04 & 0,95 & \\
\hline 1,05 & 0,96 & \\
\hline 1,06 & 0,97 & \\
\hline 1,07 & 0,98 & \\
\hline 1,08 & 0,99 & \\
\hline 1,09 & 1,00 & \\
\hline 1,10 & 1,01 & \\
\hline 1,11 & 1,02 & \\
\hline 1,12 & 1,03 & \\
\hline 1,13 & 1,04 & \\
\hline 1,14 & 1,04 & \\
\hline 1,15 & 1,05 & \\
\hline 1,16 & 1,06 & \\
\hline 1,17 & 1,07 & \\
\hline 1,18 & 1,08 & \\
\hline 1,19 & 1,09 & \\
\hline 1,20 & 1,10 & \\
\hline 1,21 & 1,11 & \\
\hline 1,22 & 1,12 & \\
\hline 1,23 & 1,13 & \\
\hline 1,24 & 1,14 & \\
\hline 1,25 & 1,15 & \\
\hline 1,26 & 1,15 & \\
\hline 1,27 & 1,16 & \\
\hline 1,28 & 1,17 & \\
\hline 1,29 & 1,18 & \\
\hline 1,30 & 1,19 & \\
\hline 1,31 & 1,20 & \\
\hline 1,32 & 1,21 & \\
\hline 1,33 & 1,22 & \\
\hline 1,34 & 1,23 & \\
\hline 1,35 & 1,24 & \\
\hline 1,36 & 1,25 & \\
\hline 1,37 & 1,26 & \\
\hline 1,38 & 1,27 & \\
\hline 1,39 & 1,27 & \\
\hline 1,40 & 1,28 & \\
\hline 1,41 & 1,29 & \\
\hline 1,42 & 1,30 & \\
\hline 1,43 & 1,31 & \\
\hline 1,44 & 1,32 & \\
\hline 1,45 & 1,33 & \\
\hline 1,46 & 1,34 & \\
\hline 1,47 & 1,35 & \\
\hline 1,48 & 1,36 & \\
\hline 1,49 & 1,37 & \\
\hline
\end{tabular}

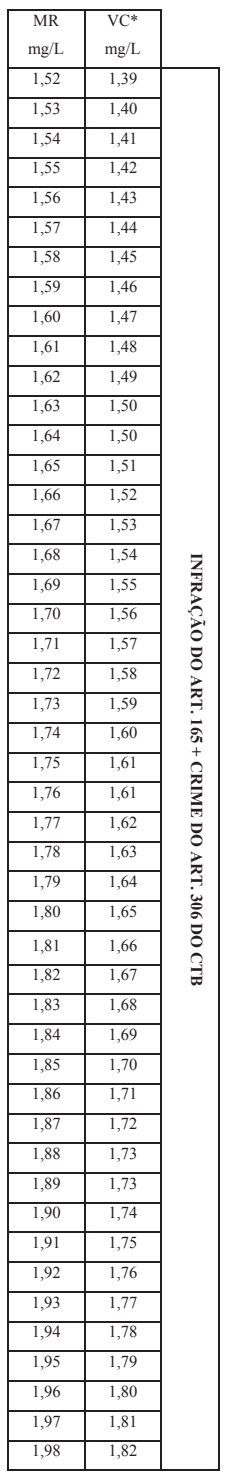

$\mathrm{MR}=$ Medição realizada pelo etilômetro $\mathrm{VC}=$ Valor considerado para a autuação

$\mathrm{EM}=$ Erro máximo admissível

Fonte: Resolução No $.432 / 2013$. 
Deve-se atentar para a diferenciação entre a infração de trânsito sob influência de álcool e o crime do Artigo 306 - com a capacidade psicomotora alterada. Sendo que o índice que delimita a infração do crime é $0,33 \mathrm{mg}$ por litro de ar expelido pelos pulmões, devendo-se também considerar a margem de tolerância do equipamento.

Quando caracterizado o crime (Art. 306 CTB), por meio do teste do bafômetro, em que o índice seja superior a $0,33 \mathrm{mg} / 1$, o infrator terá assegurado o direito a uma contraprova, conforme previsto no $\S 2^{\circ}$ do Artigo 306 do CTB, a qual será realizada com o intervalo de 15 minutos do primeiro teste.

Sobre as margens de tolerância para casos específicos, o referido regulamento buscou isentar o agente da responsabilidade administrativa em situações nada incomuns, como a de convidados de uma festa que comem bombons com licor, ou a do filho que degusta o sagu preparado por sua mãe, ou a do padre que bebe o cálice de vinho na missa, ou, entre outros exemplos, a da pessoa que utiliza depois da refeição um antisséptico bucal que contenha álcool em sua fórmula (GOMES; DE BEM, 2013, p. 80, 81).

A infração do Artigo 165, por meio do supracitado, não prevê, tão-somente, a sanção administrativa ao condutor que se encontre sob influência de álcool, mas também aqueles que estiverem sob influência de substâncias psicoativas que determinem dependência.

Substâncias psicoativas são aquelas que alteram o psiquismo. Diversas dessas drogas possuem potencial de abuso, ou seja, são passíveis da autoadministração repetida e consequente ocorrência de fenômenos, como uso nocivo (padrão de uso de substâncias psicoativas que está causando dano à saúde física ou mental), tolerância (necessidade de doses crescentes da substância para atingir o efeito desejado), abstinência, compulsão para o consumo e a dependência (síndrome composta de fenômenos fisiológicos, comportamentais e cogniti- 
vos no qual o uso de uma substância torna-se prioritário para o indivíduo em relação a outros comportamentos que antes tinham maior importância).

As substâncias psicoativas são divididas em três grupos: 1. Drogas psicoanalépticas ou estimulantes do SNC (cocaína, anfetamina, nicotina, cafeína etc.).

2. Drogas psicolépticas ou depressoras do SNC (álcool, benzodiazepínicos, barbitúricos, opioides, solventes etc.).

3. Drogas psicodislépticas ou alucinógenas (Cannabis Sativa, LSD, fungos alucinógenos, anticolinérgicos etc.). [...] Álcool

O álcool é a substância psicoativa usada mais larga e precocemente (a primeira experiência tipicamente ocorre na adolescência) na vida. Trata-se de um depressor do sistema nervoso central (SNC), cujo mecanismo de ação neurofisiológico ainda não está totalmente esclarecido. Em pequenas quantidades, provoca sensação de bem-estar, expansividade, relaxamento e desinibição comportamental, além de comprometimento da coordenação motora (TAMELINI; MONDONI, 2009, p. 1, 4).

A detecção das demais substâncias psicoativas ainda é limitada, efetuando-se por meio de exame clínico ou prova testemunhal, haja vista ainda não estar regulamentado em nossa legislação o equipamento específico para a detecção de substâncias ilícitas adversas. Conforme noticiado por Grabauska (2015, p. 3) o aparelho de nome "Salivometro", ainda está em fase de testes, sendo que em cinco minutos pode detectar a presença de substâncias ilícitas (cocaína, THC, benzodiazepínicos, opioides, anfetaminas e metanfetaminas) ingeridas pelo condutor do veículo, por meio de uma simples amostra de saliva.

No que tange ao Artigo 165-A, trata-se da infração cometida pelo agente que se recusa a efetuar o teste do etilômetro, exame clínico, perícia ou qualquer procedimento que permita certificar influência de álcool ou outra substância psicoativa, o qual possui o mesmo rigor punitivo do Artigo 165. 
Todo condutor suspeito tem obrigação de submeter-se ao teste do bafômetro quando requisitado, e o bafômetro é considerado como meio de prova que o motorista não ingeriu bebidas alcoólicas, e a recusa seria interpretada como assumir que bebeu (MARTINS, 2014, p. 36).

Entretanto, é importante ressaltar que não é permitido à autoridade obrigar coercitivamente o agente a realizar o teste do etilômetro, devendo, no entanto, informá-lo das penalidades e medidas administrativas impostas a quem se recusa ao referido procedimento (PERRENOUD, 2014). Ou seja, trata-se do exercício do direito constitucional de não produzir provas contra si mesmo, embora não o exima das penalidades.

Em contrapartida, alguns doutrinadores afirmam que o referido artigo fere o princípio da legalidade, visto que a sua realização (etilômetro) é imposta em virtude do temor referente às penalidades previstas no Artigo 165-A. Sendo que tal preceito fere o princípio constitucional da não autoincriminação (GOMES; DE BEM, 2013, p. 36).

Destaca-se também que a recusa ao teste no etilômetro, ou outro meio de comprovação, não exclui o agente da apreciação do crime do Artigo 306 do CTB, o delito pode ser comprovado por meio de prova testemunhal ou exame clínico que ateste a alteração da capacidade psicomotora do indivíduo.

O crime do Artigo 306 do CTB poderá incidir de duas maneiras, a primeira onde o agente se envolve em acidente de trânsito, estando com a capacidade psicomotora alterada, tratando-se de um crime de perigo concreto. Conforme aduz Pereira (2009, p. 5), nos crimes de perigo concreto, o agente assume o risco consciente de produzir um resultado danoso a um bem tutelado, sendo esse resultado passível de ser atingido por meio da execução de determinada conduta.

A segunda maneira de incidir o referido delito é por meio da simples comprovação da alteração da capacidade psicomotora durante fiscalização de trânsito (índice superior a $0,33 \mathrm{mg} / 1$, prova pericial ou testemunhal), caracterizando-se como crime de perigo abstrato. Este, para Pereira (2010, p. 5), é aquele que possui perigo residente somente 
na conduta (ato), em que a probabilidade do resultado se dá pela lógica de um possível resultado danoso.

Já Gomes e De Bem (2013) trazem um novo conceito para o crime do Artigo 306:

A categoria que se encaixa com perfeição no novo tipo penal é a do perigo abstrato de perigosidade real [...] Uma vez acolhida a nova linha dogmática do perigo abstrato de perigosidade real, está rompida a velha dicotomia perigo abstrato (presumido) e perigo concreto. Nasceu um tercius: perigo abstrato de perigosidade real. Só existiria o crime citado quando houvesse superação de um determinado risco-base, retratado na condução anormal (GOMES; DE BEM, 2013, p. 96).

Tratando-se de medidas administrativas referentes à infração supracitada, tem-se com fundamento para o recolhimento da Carteira Nacional de Habilitação $(\mathrm{CNH})$, o próprio Artigo 165, que prevê retenção do documento, por prazo suficiente até que o condutor comprove não estar sob influência de substância psicoativa. Já a retenção do veículo dá-se com fulcro no Artigo 270, $\S 4^{\circ}$., devendo ser apresentado um condutor habilitado em tempo hábil, sob pena de recolhimento ao depósito (credenciado pelo DETRAN).

Outra infração administrativa prevista no Artigo 165, talvez a de maior rigidez, é a suspensão do direito de dirigir por 12 meses imposta pelo DETRAN, depois de findada a fase recursal da infração.

Por fim, é oportuno destacar que um dos fatores mais rigorosos da aplicação da referida norma é o valor das multas, que a partir da alteração dada pela Lei 13.281/2016 passou a ser de R $\$ 2.934,70$, para infrações do Artigo 165 e 165-A, sendo que ao condutor reincidente na infração no período de 12 meses se aplicará o valor em dobro.

\section{Tóxicos X CONDUÇÃo de VEÍCULOS}

Com o advento da Lei 11.343 em 2006 (Lei de Tóxicos), o que era tratado como crime passou a ser compreendido como uma questão 
de saúde pública. A partir disso, ocorreu uma descarcerização no que tange ao crime de posse de drogas, haja vista que no texto do Artigo 28 da referida Lei não existe menção a penas privativas de liberdade, ao contrário do que previa a Lei $\mathrm{N}^{\circ}$. 6.368/1976, onde dispunha em seu Artigo 16 pena privativa de liberdade de até dois anos para o crime de posse de entorpecente.

Alguns leigos analisam a descarcerização como descriminalização da posse de drogas, contudo, é importante ressaltar que a flagrância desse delito ainda resulta na lavratura do Termo Circunstanciado, documento destinado a registrar o flagrante de crimes de menor potencial ofensivo, cuja pena máxima cominada não ultrapasse dois anos ou multa.

A primeira mudança trazida com a Lei de tóxicos de 2006 foi a alteração da terminologia Entorpecente por Droga, o que deixou de restringir a norma apenas à categoria de entorpecentes ou de substâncias causadoras de dependência física ou psíquica, ampliando para todas as substâncias ou produtos com potencial de causar dependência. Desta feita, as substâncias ilegais deverão ser condicionadas à inserção em dispositivo legal competente, publicadas periodicamente pelo Ministério da Saúde, por meio da ANVISA (Portaria 344 de 1998) (RAMOS, 2008, p. 3).

A referida lista é utilizada como parâmetro de aplicação da infração do Artigo 165 do CTB, no que tange à fiscalização de condutores sob o efeito de substâncias psicoativas. Nesse sentido, é importante ressaltar que o usuário de drogas que conduzir um veículo com a capacidade psicomotora alterada poderá sofrer as sanções previstas no Artigo 306 do CTB, assim como o condutor embriagado. A única peculiaridade na fiscalização dos tóxicos é o meio de comprovação, haja vista que a embriaguez comprova-se por meio do teste de alcoolemia ou prova testemunhal, já o efeito das drogas ainda se restringe à prova pericial (médico) ou testemunhal (autoridade policial), embora já existam tecnologias de detecção imediata, não há outra forma de comprovação aceita em nosso ordenamento.

Conforme o Código de Trânsito Brasileiro (CTB), o condutor flagrado pela autoridade competente de trânsito ingerindo substância 
entorpecente será autuado pelo Artigo 165, o qual prevê sanção administrativa de recolhimento da Carteira Nacional de Habilitação $(\mathrm{CNH})$ pelo prazo suficiente até que comprove não estar sob influência de drogas, além da lavratura do termo circunstanciado por posse de entorpecentes (art. 28 da Lei 11.343/2006). Caso se comprove a alteração da capacidade psicomotora, o infrator deverá ser conduzido à delegacia de polícia para a lavratura do flagrante, haja vista ter cometido crime de trânsito previsto no Artigo 306 do CTB, assim como exemplifica o quadro a seguir:

\begin{tabular}{|c|c|c|}
\hline Usuário de drogas & $\begin{array}{c}\text { Condutor sob efeito de } \\
\text { drogas }\end{array}$ & $\begin{array}{l}\text { Condutor com a capacida- } \\
\text { de psicomotora alterada } \\
\text { pela ingestão de drogas }\end{array}$ \\
\hline \multirow{3}{*}{$\begin{array}{l}\text { Lavratura de Termo } \\
\text { Circunstanciado (BO/ } \\
\text { TC) em face do cometi- } \\
\text { mento do crime previsto } \\
\text { no Art. } 28 \text { da Lei } N^{\circ} \text {. } \\
\text { 11.343/2006 } \\
\text { (Materialidade - Droga). }\end{array}$} & $\begin{array}{l}\text { Lavratura de Termo Cir- } \\
\text { cunstanciado (BO/TC) em } \\
\text { face do cometimento do } \\
\text { crime previsto no Art. } 28 \\
\text { da Lei } N^{\circ} .11 .343 / 2006 . \\
\text { (Materialidade - Droga). }\end{array}$ & $\begin{array}{l}\text { Lavratura de Termo Circuns- } \\
\text { tanciado (BO/TC) em face } \\
\text { do cometimento do crime } \\
\text { previsto no Art. } 28 \text { da Lei } N^{\circ} \text {. } \\
11.343 / 2006 \\
\text { (Materialidade - Droga). }\end{array}$ \\
\hline & & $\begin{array}{l}\text { Autuação de trânsito com } \\
\text { fulcro no Art. } 165 \text { do CTB. }\end{array}$ \\
\hline & $\begin{array}{l}\text { Autuação de trânsito com } \\
\text { fulcro no Art. } 165 \text { do CTB. }\end{array}$ & $\begin{array}{l}\text { Apresentação do infrator na } \\
\text { Delegacia de Polícia para a } \\
\text { lavratura de Auto de Prisão } \\
\text { em Flagrante pelo cometi- } \\
\text { mento do crime previsto no } \\
\text { Art. } 306 \text { do CTB. }\end{array}$ \\
\hline
\end{tabular}

Quadro 1 - Sanções previstas a usuários de drogas.

Fonte: Elaborado por meio de dados coletados das leis: $\mathrm{N}^{\circ}$. 9.503/1997 (CTB) e $\mathrm{N}^{\circ}$. 11.343/06 (Lei de Tóxicos).

Encerrando as discussões acerca dos tóxicos, é importante ressaltar que, até então, muitos desconhecem que a aplicabilidade da norma se estende a usuários de drogas, não ficando restrita apenas a condutores embriagados, mas sim a qualquer motorista que possa gerar perigo de dano 
por meio da alteração de seus sentidos ou capacidade psicomotora, razão pela qual o presente estudo possui caráter explicativo e informativo.

\section{Método}

A presente pesquisa se enquadra como uma pesquisa quantitativa, de acordo com Creswell (2010), esse método apresenta expressões numéricas, e, por meio dos resultados obtidos, o pesquisador faz interpretações. Tais aferições fomentam os dados exibidos, para que tenham maior exatidão e com a análise quantitativa, aprofundem os resultados obtidos.

Além disso, é também de cunho descritivo, visto que os dados obtidos foram descritos. Segundo Gil (2008, p. 28), essa visão "tem como objetivo primordial a descrição das características de determinada população ou fenômeno ou o estabelecimento de relações entre variáveis". Os resultados foram adquiridos por meio de dados secundários, em forma numérica, disponibilizados pela Polícia Rodoviária Estadual de Cruz Alta. Essas fontes podem ser compreendidas como pesquisas documentais, uma vez que se investigam documentos verídicos de fontes fiéis (GERHARDT et al., 2009, p. 69).

A amostra da pesquisa concentra-se no número de acidentes ocorridos entre 2012 a 2016 na região noroeste do Rio Grande do Sul, por meio dos dados obtidos pela Polícia Rodoviária Estadual de Cruz Alta RS. Determinou-se tal localidade como amostragem, em virtude da disponibilidade dos dados da referida instituição. Ainda, foram utilizados dados disponibilizados pelo site do DETRAN, para fazer um comparativo a nível estadual (RS) com os indicadores da polícia de Cruz Alta.

A análise e o tratamento dos dados ocorreram por meio da análise estatística dos dados, a qual, segundo Silveira e Cordova (2009, p. 82), apontam que se refere ao processamento de dados, por meio da geração, apresentação e interpretação destes. Assim, os dados obtidos foram analisados e comparados para se identificar se houve aumento ou redução do número de mortes e lesões corporais, ocasionados por acidentes automobilísticos que envolvam o consumo de substâncias psicoativas por parte dos condutores. Por fim, buscou-se, também, fazer uma aná- 
lise em questão de gênero, verificando se mulheres ou homens incidem com maior frequência no referido crime.

\section{AnÁlise de dAdos}

A partir da coleta e análise de dados, buscou-se nos parágrafos seguintes apontar os resultados obtidos. Dessa forma, no quadro a seguir (Quadro 2), destaca-se o número de acidentes com lesões corporais, no período de 2012 a 2016.

\begin{tabular}{|c|c|}
\hline \multicolumn{2}{|c|}{ Acidentes com lesões em rodovias estaduais da região de Cruz Alta } \\
\hline Ano & Total \\
\hline 2012 & 72 \\
\hline 2013 & 91 \\
\hline 2014 & 81 \\
\hline 2015 & 41 \\
\hline 2016 & 59 \\
\hline
\end{tabular}

Quadro 2 - Número de acidentes com Lesões Corporais em rodovias estaduais da região de Cruz Alta, no período de 2012 a 2016.

Fonte: Brigada Militar - Sistema Estatístico do CRBM (Comando Rodoviário da Brigada Militar).

Por meio do Quadro 2, é possível observar o número total de acidentes com lesões corporais ocorridos na cidade de Cruz Alta - RS, no período de 2012 a 2016. Aponta-se, nesse sentido, um aumento no ano de 2013, o qual, nos anos posteriores - 2014 e 2015 - reduziu-se gradativamente. Contudo, novamente, em 2016, observou-se um pequeno acréscimo, todavia ainda inferior aos anos de 2012 e 2013, períodos em que estava sendo implantada a Lei.

Vale ressaltar que a Lesão Corporal Culposa positivada no Código de Trânsito Brasileiro em seu Artigo 303 prevê pena de detenção de seis meses a dois anos e suspensão ou proibição de se obter a permissão ou a 
habilitação para dirigir veículo automotor, com majorante de $1 / 3$ à metade da pena, aos crimes praticados sob influência de álcool ou entorpecentes.

\begin{tabular}{|c|c|}
\hline \multicolumn{2}{|c|}{$\begin{array}{c}\text { Dias da semana/acidentes com lesões em rodovias estaduais da região de Cruz } \\
\text { Alta }\end{array}$} \\
\hline Dia da Semana & Total \\
\hline Domingo & 46 \\
\hline Segunda & 47 \\
\hline Terça & 41 \\
\hline Quarta & 55 \\
\hline Quinta & 50 \\
\hline Sexta & 51 \\
\hline Sábado & \\
\hline
\end{tabular}

Quadro 3 - Número de acidentes com lesões corporais na região de Cruz Alta/dias da semana, no período de 2012 a 2016.

Fonte: Brigada Militar - Sistema Estatístico do CRBM (Comando Rodoviário da Brigada Militar).

Com base no Quadro 3, é possível perceber a ocorrência de acidentes com lesões corporais por dia da semana, na cidade de Cruz Alta - RS, onde se verifica que os três maiores índices do fato ocorreram em Domingos (56 acidentes), Quintas-Feiras (55 acidentes) e Sábados (51 acidentes). Conforme o observado, destina-se atenção especial aos finais de semana (sábado e domingo), que apresentam índices elevados, possivelmente relacionados ao aumento no consumo de álcool e entorpecentes.

Já no que diz respeito ao crime de Homicídio Culposo na direção de veículo automotor, positivado no Artigo 302 do Código de Trânsito Brasileiro, observa-se que a pena (detenção, de dois a quatro anos, e suspensão ou proibição de se obter a permissão ou a habilitação para dirigir veículo automotor) possui majorante de $1 / 3$ à metade da pena, aos crimes praticados sob influência de álcool ou entorpecentes. Visto isso, observa-se a seguir o quadro demonstrativo dos acidentes com óbitos ocorridos no período de 2012 a 2016. 
LEI 12.760/2012: ESTRUTURAÇÃO NORMATIVA E ANÁLISE DA EFICÁCIA de sua aplicação no Noroeste do Rio Grande do Sul

Acidentes com MORTE em rodovias estaduais da região de Cruz Alta

\begin{tabular}{|c|c|}
\hline Ano & Total \\
\hline 2012 & 09 \\
\hline 2013 & 12 \\
\hline 2014 & 09 \\
\hline 2015 & 06 \\
\hline 2016 & 07 \\
\hline
\end{tabular}

Quadro 4 - Número de acidentes com Morte em rodovias estaduais da região de Cruz Alta, no período de 2012 a 2016.

Fonte: Brigada Militar - Sistema Estatístico do CRBM (Comando Rodoviário da Brigada Militar).

A partir do Quadro 4, observa-se que o número de acidentes com morte teve um significativo decréscimo, considerando que no ano de 2013 eram 12, e no ano de 2015 foram seis acidentes. A referida redução no número de mortes possui relação direta com a Nova Lei Seca que veio a ser aplicada gradativamente nos anos subsequentes a 2012. Entretanto, no ano de 2016 houve um pequeno aumento no número de acidentes com óbitos, porém, irrelevante ao se considerar o aumento no fluxo e na frota de veículos que ocorre anualmente.

\begin{tabular}{|c|c|}
\hline \multicolumn{2}{|c|}{$\begin{array}{c}\text { Dias da semana/acidentes com MORTE em rodovias } \\
\text { estaduais da região de Cruz Alta }\end{array}$} \\
\hline Dia da Semana & 8 \\
\hline Domingo & 5 \\
\hline Segunda & 6 \\
\hline Terça & 7 \\
\hline Quarta & 4 \\
\hline Quinta & 5 \\
\hline Sexta & 8 \\
\hline Sábado & \\
\hline
\end{tabular}

Quadro 5 - Número de acidentes com morte na região de Cruz Alta/ dias da semana, no período de 2012 a 2016.

Fonte: Brigada Militar - Sistema Estatístico do CRBM (Comando Rodoviário da Brigada Militar). 
O Quadro 5 demonstra o número de acidentes com morte ocorridos por dia da semana, e assim como constatado nas lesões corporais, observa-se que os finais de semana apresentaram maiores índices de tragédias no trânsito, visto que nos sábados e domingos foram registrados oito óbitos em ambos os dias.

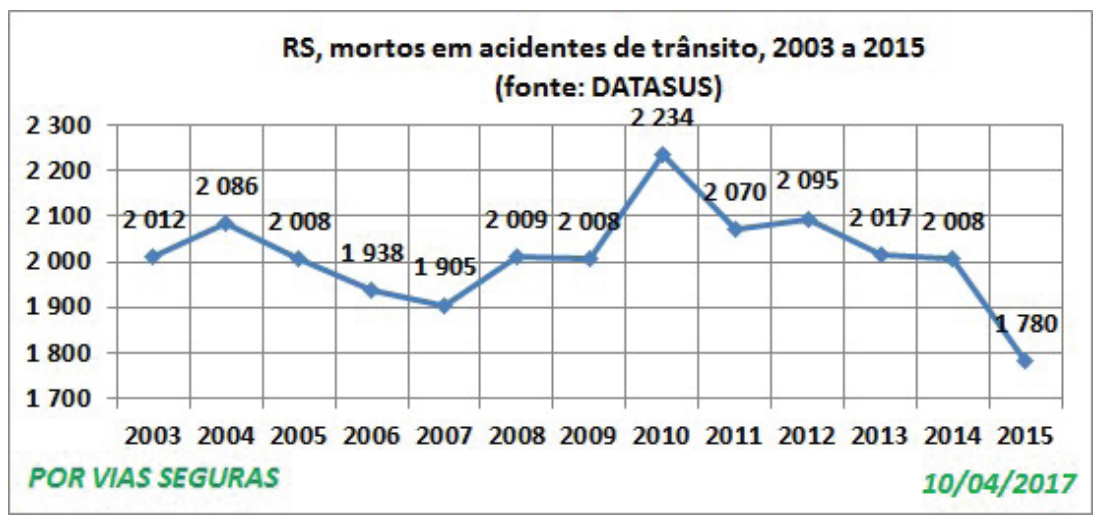

Figura 1 - Número total de Mortes em acidentes de trânsito no Estado do Rio Grande do Sul, no período de 2003 a 2015.

Fonte: http://viasseguras.com/os_acidentes/estatisticas/estatisticas_estaduais/estatisticas_de_acidentes_no_rio_grande_do_sul/acidentes_no_rio_grande_do_sul_estatisticas_do_ministerio_da_saude.

Por meio da Figura 2, é possível observar que a partir do ano de 2012 o número de óbitos ocasionados por acidentes automobilísticos no Estado vem caindo gradativamente, visto que o ano de 2015 apresentou o menor índice de mortes registrado na década (1.780 mortes).

Por fim, a Figura 2 apresenta dados referentes à pesquisa de gênero e faixa etária das vítimas fatais nos acidentes de trânsito ocorridos no período de 2012 a 2016 no Estado do Rio Grande do Sul. Considerando as informações supracitadas, é possível observar que muitas das vítimas são homens, com idades entre 24 a 30 anos, apresentando $7,8 \%$. Por sua vez, o maior índice de acidentes com o sexo feminino é de mulheres entre 64 a 75 anos de idade, o que reflete em 2,5\%. Dessa forma, como previsto, constatou-se que jovens de gênero masculino são as principais 


\begin{tabular}{|c|c|c|}
\hline \multirow[t]{2}{*}{$75+$} & $4,3 \%$ & $2,4 \%$ \\
\hline & $5,8 \%$ & $2,5 \%$ \\
\hline \multirow[t]{2}{*}{$60-64$} & $4,0 \%$ & $1,3 \%$ \\
\hline & $6,0 \%$ & $1,3 \%$ \\
\hline \multirow[t]{2}{*}{ 50-54 } & $6,6 \%$ & $1,0 \%$ \\
\hline & $5,7 \%$ & $1,0 \%$ \\
\hline \multirow[t]{2}{*}{$40-44$} & $6,6 \%$ & $1,4 \%$ \\
\hline & $6,6 \%$ & $1,6 \%$ \\
\hline \multirow[t]{2}{*}{$30-34$} & $7,3 \%$ & $1,7 \%$ \\
\hline & $7,8 \%$ & $2,3 \%$ \\
\hline \multirow[t]{2}{*}{$21-24$} & $6,2 \%$ & $0,9 \%$ \\
\hline & $5,3 \%$ & $1,4 \%$ \\
\hline \multirow[t]{2}{*}{$15-17$} & & $0,3 \%$ \\
\hline & & $0,5 \%$ \\
\hline 0-10 & & $0,8 \%$ \\
\hline
\end{tabular}

Figura 2 - Pirâmide Etária/Gênero - Vítimas Fatais no Rio Grande do Sul.

Fonte: http://www.rs.gov.br/conteudo/253958/rio-grande-do-sul-mantem-tendencia-de-reducao-de-mortes-no-transito.

vítimas fatais de acidentes de trânsitos, que em grande parte possui relação direta com o consumo de álcool e drogas quando ao volante.

\section{ConsideraÇões FinAis}

A presente pesquisa objetivou analisar a estrutura e a eficácia da nova lei seca na região noroeste do Rio Grande do Sul, no período de 2012 a 2016. Verificou-se a origem histórica da aplicabilidade do direito penal do risco (crimes de perigo abstrato e concreto) que, embora ainda não esteja pacificado, evidencia-se a sua aplicação em alguns crimes de nosso ordenamento jurídico, como foi o caso do objeto de estudo - Artigo 306 do CTB. 
No que se refere ao crime de perigo abstrato, verificou-se sua presença na criminalização do condutor que esteja com a capacidade psicomotora alterada, embora o mesmo não tenha gerado qualquer perigo de dano efetivo. Já o crime de perigo concreto, conclui-se estar presente na criminalização do condutor que se envolve em acidente de trânsito com danos materiais, estando com a capacidade psicomotora alterada, em que se evidencia o perigo de dano gerado à integridade física de terceiro(s).

Em seguida, analisou-se minuciosamente a aplicação da norma no que se refere ao consumo de álcool e entorpecentes, em que foram discutidas suas formas de aplicação no código de trânsito brasileiro, sendo estas: infrações de trânsito, medidas administrativas, bem como os crimes de trânsito ali positivados.

As discussões sobre o consumo de entorpecentes por parte de condutores revelaram um resultado surpreendente, visto que a simples conduta de consumir drogas passa a ser rigidamente criminalizada no Código de Trânsito Brasileiro. Em razão de que os infratores estarão passíveis de sanções administrativas (Art. 165 CTB e Suspensão do direito de dirigir) e do cometimento dos crimes do Artigo 306 (CTB) simultâneo com o Artigo 28 (Lei de Tóxicos).

Finda a discussão teórica, partiu-se para a coleta e análise de dados, na qual se identificou que a Nova Lei Seca tem reduzido gradativamente o número de mortes e lesões corporais no trânsito, haja vista que o rigor punitivo da lei (elevado valor das multas e a suspensão do direito de dirigir) tem gerado atitudes conscientes nos condutores, no que se refere à ingestão de substâncias psicoativas ao volante.

Desta feita, conclui-se que, embora a frota de veículos aumente ano a ano, os índices de mortes e lesões corporais se reduziram gradativamente, após a implantação da Nova Lei Seca. Fato que demonstra o impacto positivo que a norma gerou na mudança de hábito dos condutores, que por meio da rigidez da norma perceberam a gravidade do risco gerado ao conduzir um veículo sob efeito de álcool ou entorpecentes.

Por fim, é notoriamente de grande valor social a aplicação da Nova Lei Seca, visto que, conforme publicado pelo Detran/RS, "a embriaguez é uma das principais causas de acidentes" no Estado. Desta feita, após a 
análise de dados, restou comprovada a eficácia da lei, por meio das inúmeras vidas que foram salvas desde a sua vigência. Contudo, propõe-se uma análise no rigor punitivo dos infratores incidentes em crimes de perigo abstrato, visto que deveriam ser alvo de uma penalização mais branda se comparados àqueles que cometem crimes de perigo concreto ou de dano real. A referida propositura traria melhor equidade na aplicação da norma, bem como, maior aceitação e simpatia da população.

Em relação às limitações da pesquisa, aponta-se não haver maior base de dados, bem como, maior aprofundamento destes. Logo, sugere-se que sejam desenvolvidos estudos mais intensos a respeito da eficácia da lei, bem como, que abranjam maior população, por exemplo, um estudo que englobe todo o Estado do Rio Grande do Sul.

\section{REFERÊNCIAS}

BITENCOURT, C. R. Código penal comentado, 8. ed. São Paulo: Saraiva, 2014. BITENCOURT, C. R. Tratado de direito penal: parte geral, 8. ed. São Paulo: Saraiva, 2013.

BOTTINI, P. C. Crimes de Perigo Abstrato, 2. ed. São Paulo: Revista dos Tribunais, 2010.

BRASIL. Código de Trânsito. Lei 9.503. Institui o Código de Trânsito Brasileiro. Publicada no Diário Oficial da União de 24.9.1997. Disponível em: <http:// www.planalto.gov.br/ccivil_03/leis/L9503.htm>. Acesso em: 7 abr. 2017.

BRASIL. Decreto $\mathbf{n}^{0}$. 6.117, de 22 de maio de 2007. Aprova a Política Nacional sobre o Álcool, dispõe sobre as medidas para redução do uso indevido de álcool e sua associação com a violência e criminalidade, e dá outras providências. Publicado no Diário Oficial da União de 23.5.2007. Disponível em: $<$ http://www.planalto.gov.br/ccivil_03/_ato2007-2010/2007/decreto/d6117. htm>. Acesso em: 7 abr. 2017.

BRASIL. Lei 13.281. Altera a Lei $\mathrm{n}^{\circ}$. 9.503, de 23 de setembro de 1997 (Código de Trânsito Brasileiro), e a Lei no ${ }^{\circ}$ 13.146, de 6 de julho de 2015. Publicada no Diário Oficial da União de 5.5.2016. Disponível em: $<\mathrm{http}: / /$ 
www.planalto.gov.br/ccivil_03/_ato2015-2018/2016/lei/113281.htm>. Acesso em: 12 abr. 2017.

BRASIL. Lei Seca. Lei 11.705. Altera a Lei n. 9.503, de 23 de setembro de 1997, que 'institui o Código de Trânsito Brasileiro', e a Lei n. 9.294, de 15 de julho de 1996, que dispõe sobre as restrições ao uso e à propaganda de produtos fumígeros, bebidas alcoólicas, medicamentos, terapias e defensivos agrícolas, nos termos do $\S 4^{\circ}$. do art. 220 da Constituição Federal, para inibir o consumo de bebida alcoólica por condutor de veículo automotor, e dá outras providências. Publicada no Diário Oficial da União de 20.6.2008. Disponível em: <http://www.planalto.gov.br/ccivil_03/_ato2007-2010/2008/lei/111705. htm>. Acesso em: 9 abr. 2017.

BRASIL. Nova Lei Seca. Lei 12.760. Altera a Lei n. 9.503, de 23 de setembro de 1997, que institui o Código de Trânsito Brasileiro. Publicada no Diário Oficial da União de 21.12.2012. Disponível em: <http://www.planalto.gov.br/ ccivil_03/_ato2011-2014/2012/lei/112760.htm>. Acesso em: 12 abr. 2017.

CONTRAN. Resolução No . 432, de 23 de janeiro de 2013. Dispõe sobre os procedimentos a serem adotados pelas autoridades de trânsito e seus agentes na fiscalização do consumo de álcool ou de outra substância psicoativa que determine dependência, para aplicação do disposto nos arts. 165, 276, 277 e 306 da Lei no . 9.503, de 23 de setembro de 1997 - Código de Trânsito Brasileiro (CTB). Disponível em: <http://www.denatran.gov.br/download/Resolucoes/ (resolu\%C3\%A7\%C3\%A3o\%20432.2013c).pdf>. Acesso em: 13 abr. 2017.

CRESWELL, J. W. Projeto de pesquisa: métodos qualitativo, quantitativo e misto. Tradução de Magda França Lopes, 3. ed. Porto Alegre: Artmed, 2010.

ESTEFAM, A. Direito Penal esquematizado: parte geral, 2. ed. São Paulo: Saraiva, 2013.

FONSECA, J. J. S. Metodologia da pesquisa científica. Fortaleza: UEC, 2002.

GERHARDT, T. E. et al. Estrutura do projeto de pesquisa. In: GERHARDT, T. E.; SILVEIRA, D. T. (Orgs.). Métodos de pesquisa. Porto Alegre: UFRGS, 2009.

GIL, A. C. Métodos e técnicas de pesquisa social, 6. ed. São Paulo: Atlas, 2008 . 
GOMES, L. F.; DE BEM, L. S. Nova Lei Seca: Comentários à Lei n. 12.760, de 20/12/2012. São Paulo: Saraiva, 2013.

GONÇALVES, V. E. R. Direito penal esquematizado: parte especial. São Paulo: Saraiva, 2011.

GRABAUSKA, F. Veja como o "drogômetro" testa a presença de drogas no corpo do motorista. Publicado em 10 de outubro de 2015. Disponível em $<$ http://zh.clicrbs.com.br/rs/vida-e-estilo/noticia/2015/10/veja-como-o-drogometro-testa-a-presenca-de-drogas-no-corpo-do-motorista-4867289.html>. Acesso em: 14 abr. 2017.

JESUS, D. E. Direito Penal. São Paulo: Saraiva, 2011.

LIMA, J. S. A obrigatoriedade do exame do bafômetro está em harmonia com os princípios constitucionais? Araranguá: Universidade do Sul de SC, UNISUL, 2012. Disponível em: <www.transitobr.com.br/downloads/ trabalho_a_obrigatoriedade_do_exame_de_bafometro_esta_em_harmonia_ com_os_principios_constitucionais_..pdf $>$. Acesso em: 12 abr. 2017.

MARTINS, R. S. As implicâncias da recusa do condutor no veículo automotor em realizar o teste do etilômetro e a (in)constitucionalidade das penalidades e medidas administrativas. Trabalho de Conclusão de Curso. UNICRUZ (Universidade de Cruz Alta). Cruz Alta/RS 2014.

ONU. BRASIL. 2016. Disponível em: <https://nacoesunidas.org/campanha/ seguranca-transito/>. Acesso em: 13 abr. 2017.

PEREIRA, A. J. L. Crimes abstratos face ao princípio da ofensividade, 2010. Disponível em: <http://www.ambito-juridico.com.br/site/index.php?n link=revista_artigos_leitura\&artigo_id=7511>. Acesso em: 15 abr. 2017.

PERRENOUD, H. B. A constitucionalidade do exame obrigatório do bafômetro. Disponível em: <www.ambito-juridico.com.br/site/index.php?n link=revista_artigos\&artigo_id=7877>. Acesso em: 14 abr. 2017.

RAMOS, S. O. Comentários à Lei de Drogas. São Paulo, 2009. Disponível em: <https://www.passeidireto.com/arquivo/2780304/lei-de-drogas-comentada>. Acesso em: 21 out. 2017.

RODRIGUES, E. A. Noções sobre a teoria da imputação objetiva. In: Âmbito Jurídico, Rio Grande, XV, n. 96, jan. 2012. Disponível em: <http://www.am- 
bito-juridico.com.br/site/index.php?n_link=revista_artigos_leitura\&artigo_ id $=11035>$. Acesso em 3 nov. 2017.

SILVA, J. E. C. Risco proibido e risco permitido: a adoção da teoria da imputação objetiva pelo projeto de novo Código Penal. Revista Jus Navigandi, v. 22, n. 5.176, 2017.

SILVEIRA, D. T.; CORDOVA, F. P. A pesquisa científica. In: GERHARDT, T. E.; SILVEIRA, D. T. (Orgs.). Métodos de pesquisa. Porto Alegre: UFRGS, 2009.

TAMELINI, M. G.; MONDONI, S. M. Dependência de Substâncias Psicoativas, 2009. Disponível em: <http://www.medicinanet.com.br/conteudos/ revisoes/1545/dependencia_de_substancias_psicoativas.htm>. Acesso em: 14 abr. 2017.

SOBRE OS AUTORES:

Junior de CAmpos Junges

Universidade de Cruz Alta - UNICRUZ

Bacharel em Direito pela Universidade de Cruz Alta - UNICRUZ

CV: http://lattes.cnpq.br/5690345227880601

E-mail: jr_2011@hotmail.com

\section{Vanessa de Campos Junges}

Universidade Federal de Santa Maria - UFSM

Bacharela em Administração pela Universidade de Cruz Alta - UNICRUZ e Mestranda em Administração da Universidade Federal de Santa Maria - UFSM

CV: http://lattes.cnpq.br/7471720212092138

E-mail: vanessadecamposjunges@gmail.com 
LEI 12.760/2012: ESTRUTURAÇ̃̃o NORMATIVA E ANÁLISE DA EFICÁCIA de sua aplicação no Noroeste do Rio Grande do Sul

\section{Lauren Silva Agertt Junges}

Tecnóloga em Agroindústria pela Universidade Estadual do Rio Grande do Sul - UERGS, Pós graduada em Gestão da Segurança de Alimentos do Centro Universitário SENAC/SP e Controle de Qualidade de Alimentos da Universidade Estadual do Rio Grande do Sul - UERGS

CV: http://lattes.cnpq.br/3829728724858827

E-mail: lauren.agertt@hotmail.com

Submetido em: 1-2-2018

Aceito em: 23-2-2018 